Dr. Antonio Ramos-Arroyo

Universidad Internacional de La Rioja

@ antonio.ramos@unir.net (iD 0000-0002-4360-0490

Dr. Jesús Díaz-Campo

Universidad Internacional de La Rioja

@ jesus.diaz@unir.net iD 0000-0001-5014-8749
Recibido / Received

2 de junio de 2020

- Aceptado / Acepted 19 de junio de 2020

- Páginas / Pages De la 209 a la 223

- ISSN: $1885-365 \mathrm{X}$

\title{
Tratamiento periodístico del divorcio en la prensa española. Análisis comparativo de $A B C$ y El País
}

\section{Press coverage of divorce in Spanish press. Comparative anaylisis of $A B C$ and El País}

\section{RESUMEN:}

La legalización del divorcio en la España democrática actual supuso un importante revuelo mediático y político que incentivó la disolución del Gobierno centrista de Adolfo Suárez. Posteriormente, se aprobó otra legislación para agilizar el divorcio. Este estudio analiza el tratamiento periodístico de $A B C$ y EI País a las dos iniciativas parlamentarias a través de la teoría del framing o de los marcos, aplicando la técnica del análisis de contenido. Los periódicos no dedicaron muchos editoriales ni portadas a estas normativas, pero sí dejaron entrever el aperturismo social en la primera ley, mostrando la información desde unos marcos vinculados con la pluralidad ideológica. La segunda legislación no tuvo impacto mediático por desarrollarse en un contexto marcado por la aprobación del matrimonio homosexual y por la muerte de Juan Pablo II. El divorcio también supuso una de las reivindicaciones principales de los colectivos feministas en los primeros años de democracia, aunque no fueron de interés para la prensa.

\section{PALABRAS CLAVE:}

Divorcio; Prensa; $A B C$; El País; Framing; Iglesia católica.

\begin{abstract}
:
The divorce law which was passed by the Democratic Centre Union (UCD) caused a major political and media controversy, which wiped that party out. Lately, another law was approved. This research focus on how ABC and El País covered those legislative initiatives, according to framing theory and using content analysis methodology. Newspapers did not pay much attention to that issue, although they tried to remark the social openness of the first legislation, using frames related with political diversity. The second legislation did not have a great media impact, because it took place in a context characterized by the approval of homosexual marriage and the death of Pope Juan Pablo II. Divorce legislation was also emphasized by feminist collectives, although press did not pay much attention to them.
\end{abstract}

\section{KEY WORDS:}

Divorce; Press; ABC; El País; Framing; Catholic church. 


\section{Introducción}

El objetivo de esta investigación será analizar el tratamiento mediático de las regulaciones legislativas del divorcio en los medios impresos españoles a lo largo del periodo democrático actual. La aprobación del divorcio (en 1981) fue la primera medida de carácter social con enormes repercusiones políticas y religiosas que se aprobó en el actual periodo democrático. Se trató, por lo tanto, de una regulación legislativa con gran impacto parlamentario, mediático y cultural en la España actual. Su importancia podría no limitarse a la repercusión de dicha ley -y a la modificación legislativa que se hizo de esta materia en 2005-, ya que la base social, religiosa y política que se analizará en este trabajo es similar a otras iniciativas parlamentarias que se han producido posteriormente. Esto es, por ejemplo, la ley del aborto o el matrimonio homosexual. Por lo tanto, la aprobación del divorcio en la España democrática fue el precedente para la lucha argumental que tuvieron los políticos, la Iglesia católica y los poderes sociales en determinados temas relacionados con la familia, el matrimonio y otras cuestiones de carácter ético (Fernández del Riesgo, 2012).

El presente análisis se centra en las leyes del divorcio que se han aprobado en España desde 1978, pero interesa conocer si los resultados que se obtengan atienden al ámbito estricto de las referidas regulaciones o, además, se podrían extrapolar a las anteriormente mencionadas. De corroborarse esto, se demostraría la especial relevancia de la legalización del divorcio, por ser la pionera de todas las legislaciones de carácter social y con aspectos vinculados a la religión católica que se han aprobado en España.

Otra de las aristas que generan interés científico a este estudio es la vinculación que establecen algunos autores (Etura, 2018; Mitchell, 2019) entre el movimiento feminista y la legalización del divorcio y del aborto, por ser parte esencial para el desarrollo de estas medidas.

Montero (2004: 107-121) indica que, tras los cerca de cuarenta años de franquismo, la reaparición del movimiento feminista español «fue como un ciclón», ya que ...había urgencia por destruir el modelo de feminidad que la dictadura franquista había impuesto».

Uno de los conflictos más importantes que ha habido en el periodo democrático español entre el Gobierno y la Iglesia fue la Ley del Divorcio de 22 de junio de 1981. El motivo no fue que el Episcopado español fuera contrario a la existencia del divorcio en España (conscientes de que se trataba de una cuestión de la esfera civil), sino porque hubo una crisis interna en el partido que gobernaba propiciada por el impulso de esta medida: La Unión de Centro Democrático, conocida como la UCD (Martín de Santa Olalla (2019: 76). Por lo tanto, a juicio de este autor la primera regulación del divorcio supuso un hecho histórico especialmente relevante por las tensiones entre la Iglesia y el Estado español y por la crisis que generó esta regulación jurídica. Precisamente este estudio aborda esta situación desde el plano de la comunicación, lo que permitirá establecer conexiones y abrir nuevas líneas posteriores de estudio con otras posibles regulaciones socio-jurídicas similares o con aspectos relacionados con el caso sometido a análisis en la presente investigación.

Abordando los conflictos sociales del periodo democrático español desde otras perspectivas, hay que indicar que no solo se produjeron entre la Iglesia y el Estado. Gahete Muñoz (2017) asegura que entre los frentes abiertos por parte del feminismo hubo algunos bastantes complejos debido a la falta de acuerdo del movimiento feminista. En concreto, la autora se refiere al divorcio y a la Constitución española. Por tanto, este análisis revisará el protagonis- 
mo que tuvo en la prensa española el feminismo en un momento clave para este movimiento, como fue la legalización del divorcio tras la aprobación de la Carta Magna de 1978.

Para llevar a cabo este estudio se revisará el tratamiento periodístico de las dos iniciativas legislativas que se han presentado en España sobre el divorcio, cómo se posicionaron los medios de comunicación al respecto, qué argumentos emplearon para defender sus posturas y qué tipo de lenguaje utilizaron. Asimismo, se prestará atención a las manifestaciones de los políticos e instituciones vinculados a los asuntos de carácter social. Los diarios que se van a someter a análisis son El País y $A B C$, dos periódicos nacidos en épocas distintas y con principios distintos. Por lo tanto, se consideran dos contrapesos adecuados para desarrollar el estudio. En lo que se refiere al método de investigación que se va a emplear, va a ser la teoría de los marcos o del framing. Esta teoría analiza la forma en la que se presenta un texto periodístico a su audiencia y que «ha demostrado ser muy efectiva para estudiar qué percepción tiene el público de los hechos sociales, permitiendo resaltar la forma particular en que los tópicos o estereotipos son presentados a la audiencia» (Fernández Ramos y Antón Crespo, 2018).

Varios autores, como Semetko y Valkenburg (2000) y De Vreese, Peter y Semetko (2001), han estudiado la vinculación entre la interpretación periodística que hacen los periodistas y la forma de enmarcar una noticia. Esa manera de presentar un hecho informativo nunca será aséptica, porque informar, en cierta medida, supone una reestructuración del mundo (Sánchez Aranda y Berganza, 1999: 138). Por su parte, Entman (1991) añade que, para dar significado a las palabras que utilizan los medios y políticos, y con el fin de defender las ideas que proclaman, se utilizan marcos. Gracias a ellos se descubren los atributos de las noticias, que son constituidos desde las palabras clave, metáforas, símbolos e imágenes visuales enfatizadas en la narrativa de una noticia.

De las diversas aportaciones anteriormente señaladas se puede extraer que el framing es la teoría o la corriente teórica que estudia la vinculación que existe entre los encuadres identificados en los temas que tratan los medios de comunicación y los contextos y conexiones que influyen en la creación de una noticia. Además, revisa igualmente el impacto que pueden tener dichos enfoques de una noticia en los receptores y en los líderes políticos y sociales que aparecen en los medios.

Gomis (1987: 22) apunta la posibilidad de que las noticias que publican los medios no tienen por qué basarse en los hechos mismos, sino en aquellos aspectos de los hechos a los que ellos otorgan mayor importancia. El protagonismo que se les dé a determinados aspectos de la realidad provoca la incomodidad que suponen para los políticos y los poderes institucionales los medios informativos. Esta relación se traduce en una constante lucha en la que los primeros intentan imponer sus argumentos y razonamientos sobre los segundos (Casero Ripollés, 2009). Se trata, por lo tanto, de persuadir, que es provocar una intención, perseguir un comportamiento o crear una opinión (García Beaudoux y D’Adamo, 2016).

En el caso que centra esta investigación, el análisis determinará aquellas derivadas adyacentes al hecho legislativo en sí que supone la tramitación de dos leyes en materia del divorcio: políticos, medios, iglesia católica, colectivos sociales, etc...

Una diferencia evidente entre la prensa que se editaba en el año en que se tramitó la primera Ley del divorcio y la segunda legislación es el desarrollo de la prensa digital en el espacio temporal que hubo entre ambas. El desarrollo digital ha cambiado el ámbito periodís- 
tico tradicional, de forma que determinados sectores sociales emergentes implicados en los hechos noticiosos ahora sí tienen cabida, mientras que el modelo de prensa anterior estaba copado por los poderes fácticos que ejercían mayor presión sobre los medios (Sanmartí Roset, 2001).

Por otro lado, el riesgo que corre el periodismo digital es, a juicio de Martínez Albertos (2001), la sustitución progresiva del periodista profesional, lo que provoca la ruptura de la cadena de producción de relatos y comentarios periodísticos. Por tanto, el periodista es una figura clave y en riesgo de perder relevancia como mediador social que recoge la realidad del mundo objetivo y se la ofrece a los receptores de mensajes. Por parte de los protagonistas políticos, Roca y Cervi (2017) resaltan la lentitud con que los líderes políticos españoles de los principales partidos han adoptado herramientas de comunicación digital a lo largo de los últimos años, siguiendo con fórmulas más propias del marketing político tradicional en los diversos comicios electorales que se han celebrado en España en los últimos cinco años.

\subsection{Periódicos analizados}

Partiendo de los conceptos teóricos referidos anteriormente, este análisis se centrará en la revisión del tratamiento que hicieron los dos periódicos de ideología distinta sobre un asunto polémico de carácter social. Las referencias bibliográficas que se encontraron se limitaron a los aspectos generales e históricos de los diarios sometidos a análisis y que son susceptibles de determinar su línea editorial respecto al divorcio. Esa es la causa que justifica la revisión teórica de ambos rotativos en el presente estudio.

Se ha detectado una existencia escasa de estudios que analicen el contexto periodístico y mediático español en el que se desarrolló la segunda Ley del divorcio. La aprobación de la referida norma coincidió con la modificación legislativa por la que se aprobó el matrimonio homosexual en España.

\subsection{1. $A B C$}

Torcuato Luca de Tena fundó $A B C$ el 1 de enero de 1903, afirmando que «en política no seguirá bandera alguna para no mermar su independencia, dentro de la cual se propone vivir sin abdicar uno solo de sus fueros" (Luca de Tena, 1980: 4). ABC se mostró cercano a Adolfo Suárez, lo que provocó las presiones a este diario de grupos violentos de extrema derecha e izquierda (Olmos, 2002: 540). Sin embargo, este apoyo a la reforma democrática representada a través de la figura de Adolfo Suárez no le impidió criticar al Gobierno y a las fuerzas del orden por ejercer lo que interpretó como una cierta impunidad respecto a los grupos violentos de extrema derecha (Segado Boj, 2009).

Con la llegada de Guillermo Luca de Tena a la dirección del periódico, se impulsó la apertura liberal (Olmos, 2002: 550-559), lo que propició una línea editorial partidaria de la política de la UCD, pero con el tiempo empezó a censurar muchos de los posicionamientos de sus líderes, especialmente los referentes al nacionalismo vasco. Posteriormente, la Dirección del rotativo fue ocupada por Luis María Ansón, que dio un giro conservador al diario (Olmos, 2002: 595), atacando al Partido Socialista Obrero Español (PSOE) de Felipe González hasta 
el extremo de verse afectado el propio Estado español (Belloch, 1998: 25-27). $A B C$ «utilizó como nadie las fotografías y los dibujos" (Olmos, 2002: 644-646). Este diario también fue pionero en hacer accesible su hemeroteca a través de su página web (http://hemeroteca. ABC.es), pudiendo leer en formato PDF todos los números del periódico y la revista Blanco y Negro (Olivera Zaldúa, 2013: 78).

El propio diario señala que antepone sus principios a las simpatías partidistas, y por ello, «aunque el Partido Popular (PP) coincide con muchos de los valores que $A B C$ propugna desde antes de la existencia de esa formación, el periódico no renuncia a la crítica y a la discrepancia» (ABC, 2010: 22).

\subsubsection{El País}

El País (1976) se definió como un diario nacido

al amparo de una convicción irrenunciablemente democrática, hay que decir que la reforma política anunciada ni satisface las exigencias mínimas que el respeto a los principios de la democracia y de la libertad exigen, ni puede lograr la adhesión de las nuevas generaciones españolas.

El proyecto bajo el que nació este periódico fue la creación de un diario «riguroso conforme a patrones de prensa independiente y con referencia interna del papel jugado por algunos periódicos en la España anterior a la guerra civil» (Edo, 1994: 175-176).

Su exdirector, Juan Luis Cebrián (1976: 6), resaltó el rechazo «a las presiones que el poder político y el dinero ejercen en el mundo de la información», y destacó la «pluralidad» del diario. Este periódico dio mucha importancia a la defensa de la igualdad, la separación de la Iglesia sobre asuntos de Estado, la amnistía, las autonomías y una política familiar y sexual distinta a la que había hasta el momento y a una sociedad más abierta en lo social y con mayores libertades. El rotativo manifestó desde el principio su postura radical en estos temas, declarándose progresista y siendo conservador en lo económico y de centro en lo político (Seoane y Sueiro, 2004: 215). Para Cruz (1996: 138), con Adolfo Suárez, El País fue «excesivamente hostil». Con Felipe González «hubo vaivenes, algunos de ellos extremadamente violentos». De Leopoldo Calvo-Sotelo, El País defendía que, a pesar de ser un político con gran cultura, no tenía carisma. Por ello, la alternativa posible y deseable para EI País era el PSOE, lo que propició muchas quejas entre algunos consejeros de Prisa (Seoane y Sueiro, 2004: 151).

El País estuvo a favor de leyes de carácter progresista, algunas de ellas -como el divorcio - cuya última regulación fue aprobada por el Gobierno de Rodríguez Zapatero. Sin embargo, este diario fue muy crítico con el papel que desempeñó el exlíder socialista en algunos asuntos, lo que hizo que se pusiera en evidencia su capacidad de liderazgo y su valía al frente del Ejecutivo de la Nación (El País, 2009: 24).

\subsubsection{Comparación entre ambos diarios}

Según Canel Crespo (1999), $A B C$ da más importancia a la opinión e interpretación de la información, con agendas más atemporales en sus temas que El País y con un estilo 
Tabla 1. Tirada y difusión de los periódicos estudiados

\begin{tabular}{|l|l|l|l|l|l|}
\hline \multicolumn{1}{|c|}{ Proyectos } & \multicolumn{2}{c|}{ Tirada } & \multicolumn{2}{c|}{ Difusión } \\
\hline \multicolumn{1}{|c|}{ Fecha } & ABC & El País & ABC & El País \\
\hline $\begin{array}{l}\text { Proyecto de Ley del } \\
\text { divorcio }\end{array}$ & 22 de junio de 1981 & 163.704 & 310.829 & 131.545 & 258.837 \\
\hline $\begin{array}{l}\text { Proyecto de Ley por la que } \\
\text { se modifica el Código Civil } \\
\text { en materia de derecho a } \\
\text { contraer matrimonio }\end{array}$ & 21 de abril de 2005 & 359.985 & 582.931 & 278.167 & 453.602 \\
\hline
\end{tabular}

Fuente: OJD.

argumentativo directo, explícito y agresivo. Asimismo, El País es más sobrio y analítico en su expresión y menos comprometido con una postura. Sin embargo, ambos diarios incluyen opinión en todas las secciones del diario, no solo en la referida a este género. Lo que marca diferencias entre ambos enfoques es el tratamiento de la información gubernamental, ya que cada una de estas cabeceras mantiene su imagen e identidad propia por medio de enfoques muy sutiles que le diferencian del resto.

$A B C$ está dirigido a un nicho de lectorado monárquico, nacional, tradicional, católico e intelectual, mientras que El País encaja más en la corriente objetivista, ya que utiliza la técnica argumentativa analítica con la que da una imagen de moderado, progresista, abierto y tolerante, defensor del consenso e intelectualista. Sin embargo, «tras esa técnica se esconden claros enfoques de las noticias, expresados, más que en las páginas de opinión, en la inclusión y exclusión de matices de las informaciones, de temas, de personajes» (Canel Crespo, 1999).

Dadas las diferencias entre ambos diarios, se ha considerado que la elección de $A B C$ y $E I$ País es adecuada y suficiente para ejecutar este análisis, porque reflejan espectros políticos y sociales. No obstante, se da el caso de que «muchas investigaciones emplean un único medio como representante de toda la agenda mediática» (McCombs, 2006:101).

Un aspecto fundamental a tener en cuenta para valorar la relevancia de los dos diarios que se someten a análisis es la tirada (Manfredi, 2000) - el número de ejemplares en condiciones de ser distribuidos y vendidos que se imprimen en cada número- y la difusión - la tirada útil de una publicación que se distribuye para que llegue a sus destinatarios. La tabla 1 muestra la tirada y la difusión de cada periódico analizado en el momento de la aprobación de cada una de las dos leyes estudiadas. Para Echart et al. (2006), los mayores índices de consumo de medios de comunicación van asociados a un mayor nivel de confianza ciudadana en el Congreso de los Diputados, a un mayor interés de los ciudadanos en la gestión de los gobiernos y a una mayor participación de los ciudadanos en las elecciones a sus representantes políticos.

\subsection{La LeGALIZACIÓN DEL DIVORCIO (1981)}

En las elecciones democráticas de 1977, tanto el PSOE como el Partido Comunista de España (PCE) incluyeron en sus programas la aprobación de una ley sobre el divorcio para aprobar la disolución de la unión conyugal (Martín de Santa Olalla, 2001: 519-520). La Cons- 
titución española (BOE, 1978) afirma que «la ley regulará las formas de matrimonio, la edad y capacidad para contraerlo, los derechos y deberes de los cónyuges, las causas de separación y disolución y sus efectos». Poco después, en las segundas Elecciones Generales, (marzo de 1979) la UCD incluyó su oferta sobre el divorcio, y el democristiano íñigo Cavero se hizo cargo del proyecto de ley del divorcio al ocupar la cartera de Justicia (Martín de Santa Olalla, 2001: 526). Posteriormente, el Consejo de Ministros lo aprobó el 18 de febrero.

Cabe destacar el Artículo 87 donde se apuntaba que, de manera excepcional, el juez podía denegar el divorcio cuando se probara que ocasionaba a los hijos o al otro cónyuge perjuicios de especial gravedad. De esta manera podía romperse la opción del mutuo acuerdo entre los cónyuges para obtener el divorcio, introduciéndose una tercera parte de carácter decisorio (Martín de Santa Olalla, 2001: 519-520). Sobre las causas de divorcio, esta normativa marcaba que, algunos casos, se llegaba a exigir el cese efectivo de la convivencia conyugal durante, al menos, cuatro años ininterrumpidos.

En cuanto a las causas de separación que se apuntaban, hay que resaltar que hacían referencia al abandono justificado del hogar, las relaciones sexuales extraconyugales, la conducta injuriosa o cualquier otra violación grave de los deberes conyugales (BOCG, 1980). También se incluía cualquier violación grave de los deberes respecto de los hijos comunes, la condena a pena de privación de libertad por tiempo superior a seis años y razones de alcoholismo, la toxicomanía o las perturbaciones mentales.

Con la entrada de Francisco Fernández Ordóñez en sustitución de Iñigo Cavero, se rehízo totalmente el proyecto del divorcio. Las principales novedades que recogía este proyecto eran la reducción de los plazos, la ampliación del campo de las decisiones por mutuo consentimiento sin comprobación de las causas, la introducción de una forma equivalente al divorcio por decisión unilateral y la restricción de la facultad decisoria del juez.

El 22 de junio el proyecto de legalización del divorcio alcanzaba rango de ley gracias a los votos de los socialdemócratas de la UCD, PSOE, PCE, Minoría Catalana, Esquerra Republicana de Catalunya (ERC) y Partido Nacionalista Vasco (PNV), votando en contra el resto de los diputados de la UCD y los de Alianza Popular (AP) (Martín de Santa Olalla, 2001 546).

\subsection{Segunda legisLación del divorcio: El divorcio eXPRÉS}

EI PSOE incluyó en su programa electoral a las Elecciones Generales de 2004 abordar una nueva legislación sobre el divorcio en España para simplificar los procesos de separación y divorcio, suprimiendo el divorcio causal y permitiendo el acceso directo al divorcio sin necesidad de previa separación (PSOE, 2004: 33).

La «Ley 15/2005, de 8 de julio, por la que se modifican el Código Civil y la Ley de Enjuiciamiento Civil en materia de separación y divorcio» acaba con las causas de separación y divorcio, permitiendo tanto una separación como un divorcio de forma unilateral y sin causa. El único requisito que se exige para solicitar la separación o el divorcio es que hayan transcurrido tres meses desde la celebración del matrimonio (Domínguez, 2007). Además, con la aprobación de esta ley, el matrimonio puede concluir con la manifestación realizada por uno o por los dos cónyuges de que ya no mantienen ese consentimiento (divorcio), o de que lo mantienen pero sujeto a la separación (Montero Aroca, Flors Matíes y Arenas García, 2006: 68). 
Con esta regulación se pretendió reforzar la libertad de decisión de los padres respecto del ejercicio de la patria potestad, ya que son ellos quienes

deberán decidir si la guarda y custodia se ejercerá sólo por uno de ellos o bien por ambos de forma compartida. En todo caso, determinarán, en beneficio del menor, cómo éste se relacionará del mejor modo con el progenitor que no conviva con él, y procurarán la realización del principio de corresponsabilidad en el ejercicio de la potestad (BOE, 2005: 24459).

\subsection{Objetivos e hipótesis}

El objetivo de este estudio es analizar la controversia política y mediática que surgió en España acerca del divorcio como antesala a otra serie de conflictos emanados en el periodo histórico democrático actual que pudieran contener bases éticas, sociales, religiosas y políticas similares, según la revisión científica que aporta la teoría del fraiming.

Como primera hipótesis se apunta que en las confrontaciones generadas en la prensa española a consecuencia de las leyes del divorcio que se han aprobado en el periodo democrático se han impuesto los marcos progresistas sobre los marcos conservadores. Esto ha tenido consecuencias axiológicas para la sociedad, ya que consiguieron promover valores alejados a la religión católica, impulsando el pluralismo filosófico - frente al monismo filosófico- como marco para el tratamiento de los asuntos que guardan relación con los valores.

La segunda hipótesis plantea que la prensa escrita española se ha posicionado siempre a favor o en contra de las iniciativas parlamentarias que han regulado el divorcio en función de la subcultura con la que se identifican editorialmente y no con la postura adoptada por los partidos políticos sobre estas legislaciones. Además, los periódicos analizados se han postulado de manera clara acerca del asunto abordado, siendo coherentes con sus principios editoriales.

Como tercera hipótesis, se considera que varios de los marcos mediáticos y políticos que emanan del estudio evocan a otros asuntos que se han regulado en el ámbito jurídico posteriormente. Esto implicó que la legalización del divorcio fue pionera en el tratamiento mediático y la confrontación política, religiosa y social de España.

Se ha sometido a análisis el Proyecto de Ley del divorcio y el Proyecto de Ley por la que se modifican el Código Civil (aprobado el 22 de junio de 1981) y la Ley de Enjuiciamiento Civil en materia de separación y divorcio (aprobado el 21 de abril de 2005). Se ha fijado como referente el estudio de los proyectos de ley - al igual que han hecho otros estudios precedentes (Rodríguez-Luque, 2008) - porque recogen el periodo de elaboración de la ley en el que se establecen posturas, se debate y se negocia en las Comisiones Legislativas y en el Pleno del Congreso de los Diputados las materias que sometemos a análisis, según marca el artículo 75 de la Constitución española de 1978.

\section{Diseño y método}

El modelo metodológico empleado ha sido el análisis de contenido. Para Berelson (1952: 17), se trata de una técnica de investigación para la descripción objetiva, sistemática y cuantitativa del contenido manifiesto de la comunicación. 
Andréu (2001) plantea un modelo de análisis de contenido semántico muy práctico para este estudio, basado en un método que revisa las relaciones entre los temas tratados en un texto. Estudios sobre la teoría del framing como el de Fernández Ramos y Antón Crespo (2018) también emplean este modelo de análisis como herramienta para investigar sobre los encuadres que plasma la prensa en su labor de reflejar los hechos noticiosos a sus lectores.

La matriz de este esquema de análisis debe permitir recoger varias formas de presentación del mismo en función de la intencionalidad del contexto. La unidad de análisis es la cláusula (el fragmento del texto) que se adapta a la matriz definida (Porta y Silva, 2003).

Tras haber definido el análisis de contenido planteado, se ha aplicado a los periódicos $A B C$ y El País. La primera razón por la que se ha empleado la prensa escrita es que los periódicos generan una situación de recepción de los mensajes bien diferenciada respecto al resto y permiten una reflexión mayor que los medios audiovisuales (D’Adamo, García Beaudoux y Freidenberg, 2007: 71). Además, los periódicos sometidos a estudio han sido los únicos diarios generalistas y de tirada nacional que se han editado en el periodo histórico analizado. También se ha valorado la accesibilidad a las fuentes, mucho más fácil que a otras como la televisión o la radio.

Se ha dado especial relevancia al género del editorial, al ser el más importante para conocer la opinión de un periódico sobre un asunto periodístico. También se han estudiado las columnas, los artículos y los géneros mixtos (Martínez Albertos, 1991).

\section{Trabajo de campo y análisis de datos}

Para el desarrollo del modelo metodológico empleado se ha elaborado un análisis que parte de una serie de categorías en función de los objetivos y las hipótesis formuladas. De este modo, se ha abordado el estudio partiendo de las unidades genéricas, que son periódicos revisados. Se ha tomado como referencia el día de la aprobación de cada una de las iniciativas legislativas en el Congreso de los Diputados, acotando así el estudio a la semana anterior y la posterior a esa fecha. De este modo, la recopilación de información queda según se indica en la tabla 2:

Tabla 2. Periodos de análisis

\begin{tabular}{|c|c|c|c|c|}
\hline Legislación & $\begin{array}{c}\text { Fecha de } \\
\text { aprobación }\end{array}$ & Rango de estudio & $A B C$ & El País \\
\hline $\begin{array}{l}\text { Proyecto de Ley del } \\
\text { divorcio }\end{array}$ & $7 / 4 / 1981$ & $\begin{array}{c}\text { 31/3/1981-14/4/1981 } \\
\text { Los lunes no se editaba } \\
\text { prensa }\end{array}$ & 13 días & 13 días \\
\hline $\begin{array}{l}\text { Proyecto de Ley por la que } \\
\text { se modifica el Código Civil } \\
\text { en materia de derecho a } \\
\text { contraer matrimonio }\end{array}$ & $21 / 4 / 2005$ & $14 / 4 / 2005-28 / 4 / 2005$ & 15 días & 15 días \\
\hline
\end{tabular}

Fuente: Elaboración propia. 
La tabla 2 muestra las fechas de estudio correspondientes a la semana anterior, la posterior y al día de la aprobación de los proyectos de ley de las dos leyes del divorcio.

Asimismo, para la elaboración del análisis se han apuntado las unidades de registro (segmentos de contenidos periodísticos cuyo análisis era relevante para la investigación, como las noticias, entrevistas, imágenes, editoriales...), que están enfocadas en la codificación y en el recuento frecuencial (Porta y Silva, 2003).

El siguiente paso ha sido agrupar todos los resultados obtenidos en el análisis, siguiendo el esquema de Porta y Silva y añadiendo -además - los marcos genéricos planteados por Semetko y Valkenburg (2000). Estos frames son cinco tipos de encuadres que son considerados un repertorio estándar de indicadores analíticos (a los que hay que sumar los expuestos anteriormente). La finalidad es poder transformar los resultados obtenidos en unidades de estudio medibles de forma segmentada, respetando su significado, pero de tal forma que se puedan encasillar para definir de forma genérica la información que contiene cada frame.

Con la finalidad de diseñar un modelo válido de análisis que refleje los marcos genéricos, se han tenido en cuenta los encuadres que aparecen en las frases, los sustantivos, adjetivos de los textos que se han analizado, así como el resto de los elementos periodísticos que condicionan la presentación de la información y el entendimiento por parte del lector, como por ejemplo las imágenes. Para realizar el libro de códigos, se ha elaborado un esquema numérico que, en función del número de repeticiones, ha servido para evaluar los resultados obtenidos. Los datos de identificación básicos son el número de unidad de análisis de registro, la fecha de publicación y el periódico.

La descripción formal es: posición (a favor o en contra), ubicación, fuente (nombre) y profesión. En cuanto a la información: el género de la información y sección. En el apartado de opinión, se encuentra el editorial, la columna y el artículo. Respecto a las imágenes, se diferencia entre fotografía, grafismo, viñeta o sin imagen. Finalmente, se han incluido los marcos genéricos (Semetko y Valkenburg, 2000) que son el encuadre genérico de atribución de responsabilidad (asignación de responsabilidades a instituciones políticas o individuos), de interés humano (centrando la historia en un individuo como un ejemplo o enfatizando las emociones), de conflicto (estudia los conflictos entre las partes o individuos), de moralidad (aspectos relacionados con la moral del ser humano) y de consecuencias económicas (destacar las consecuencias económicas para las audiencias).

\section{Resultados}

Los resultados aquí incluidos son una selección de aquellos datos y tablas más relevantes de todo el estudio realizado.

El País dedicó un único editorial a la primera legislación del divorcio (mostrándose a favor) y ninguno a la segunda, y $A B C$ uno a la primera Ley (en la que no se evidencia una postura concreta) y ninguno a la segunda. En cuanto a los artículos y noticias de El País, hubo más sobre la primera Ley que sobre la segunda. Acerca de esta última legislación, $A B C$ no tuvo ninguna publicación sobre los mencionados géneros periodísticos. Siguiendo con la segunda normativa del divorcio, no aparecieron entrevistas en ningún periódico.

Respecto a las imágenes y comparando ambas leyes y periódicos, donde más aparecieron fue en El País con la segunda Ley del divorcio (14 frente a cuatro de $A B C$; y, en lo que se 
Tabla 3. Ubicación de los géneros informativos y mixtos (en unidades de registro)

\begin{tabular}{|l|c|c|c|c|c|c|}
\hline & Portada & $\begin{array}{c}\text { Interior } \\
\text { par }\end{array}$ & $\begin{array}{c}\text { Interior } \\
\text { impar }\end{array}$ & Contraportada & Doble & Total \\
\hline $1^{\text {a }}$ Ley divorcio ABC & 3 & 4 & 12 & - & - & 19 \\
\hline $1^{\text {a }}$ Ley divorcio El País & 1 & 3 & 5 & - & - & 9 \\
\hline $2^{\text {a }}$ Ley divorcio ABC & 1 & 3 & - & - & 4 \\
\hline $2^{\text {a }}$ Ley divorcio El País & 2 & 10 & 4 & - & 1 & 17 \\
\hline
\end{tabular}

Fuente: Elaboración propia.

refiere a la primera Ley, hubo seis en el diario de Prisa y ninguna en $A B C$ ). En todos estos casos se trataba de fotografías, salvo en El País con la segunda ley, que también hay grafismos.

Según recoge la tabla 3, la mayoría de las portadas de periódicos con informaciones sobre los asuntos sometidos a análisis aparecieron en $A B C$ con la primera Ley del divorcio. $E I$ País ubicó en la sección de sociedad las noticias, crónicas e imágenes con la segunda Ley del divorcio; $A B C$ solo lo hizo con una entrevista de la primera Ley.

La tabla 4 señala que $A B C$ tuvo más declaraciones sin firma o firmadas por periodistas de este medio que El País en la primera Ley. Sin embargo, en la segunda ocurrió lo contrario. El único posicionamiento de la Iglesia católica acerca de las leyes analizadas fue en $A B C$ con la primera Ley del divorcio. Los dos periódicos publicaron más declaraciones de miembros de la UCD en contra que a favor de la primera Ley. Comparando ambas leyes del divorcio, $A B C$ fue el periódico que más sacó en portada la primera legislación, seguida de la segunda Ley en El País. En el primer caso, destaca el número de unidades de registro que aparecieron en las páginas interiores impares. En el último caso, la mayor parte de la información estuvo en las páginas interiores pares.

Tabla 4. Declaraciones sobre las leyes del divorcio

\begin{tabular}{|l|c|c|c|c|}
\hline \multicolumn{1}{|c|}{ Fuente } & $\begin{array}{c}\text { Primera ley } \\
\text { ABC }\end{array}$ & $\begin{array}{c}\text { Primera ley } \\
\text { El País }\end{array}$ & $\begin{array}{c}\text { Segunda } \\
\text { ley ABC }\end{array}$ & $\begin{array}{c}\text { Segunda ley } \\
\text { EI País }\end{array}$ \\
\hline Iglesia o asociación Católica & 1 & - & - & 1 \\
\hline Colectivos feministas & - & - & - & - \\
\hline Cultura & - & 4 & - & 1 \\
\hline Experto en derecho & 1 & 1 & - & 6 \\
\hline Periodista/agencia/ sin firma & 9 & 1 & - & 5 \\
\hline PSOE & 4 & 2 & - \\
\hline PP/AP/C. Democrática & 3 & - & - \\
\hline P. Comunista/ IU & 2 & - & - & 2 \\
\hline Grupo Centrista/UCD/CDS & 6 & - & 1 & - \\
\hline Otros & & & - & - \\
\hline
\end{tabular}

Fuente: Elaboración propia. 
Tabla 5. Marcos genéricos aparecidos en los periódicos

\begin{tabular}{|l|c|c|c|c|}
\hline & $\begin{array}{c}\text { Primera ley } \\
\text { ABC }\end{array}$ & $\begin{array}{c}\text { Primera ley } \\
\text { EI País }\end{array}$ & $\begin{array}{c}\text { Segunda ley } \\
\text { ABC }\end{array}$ & $\begin{array}{c}\text { Segunda ley } \\
\text { El País }\end{array}$ \\
\hline $\begin{array}{l}\text { Atribución de } \\
\text { responsabilidad }\end{array}$ & 17 & 7 & 4 & 15 \\
\hline Interés humano & 5 & 7 & 6 & 8 \\
\hline Conflicto & 29 & 13 & - & 7 \\
\hline Moralidad & 4 & 7 & - & 3 \\
\hline $\begin{array}{l}\text { Consecuencias } \\
\text { económicas }\end{array}$ & - & 2 & - & 2 \\
\hline Total & 55 & 36 & 10 & 35 \\
\hline
\end{tabular}

Fuente: Elaboración propia.

La tabla 5 recoge los modelos de marcos genéricos en las filas y las leyes y periódicos analizados en las columnas. Como se observa en esta tabla, el mayor número de marcos genéricos recogidos en los textos analizados fue en $A B C$ con la primera Ley del divorcio, seguido de El País con esta misma Ley, aunque muy de cerca de la segunda Ley en este último periódico. El marco que más apareció es el de conflicto en el $A B C$ con la primera Ley del divorcio.

El marco genérico que más apareció es el de conflicto, en los textos periodísticos de $A B C$ acerca de la primera Ley del divorcio, seguido del de atribución de responsabilidad, también en la información sobre la primera Ley del divorcio en $A B C$. El encuadre de consecuencias económicas aparece tan solo en El País, en ambas leyes.

Otro aspecto que hay que destacar en los resultados obtenidos es el material fotográfico. En este caso, El País fue el periódico que más marcos genéricos recoge en lo referido a la primera ley del divorcio, seguido de la segunda ley en este mismo diario. Respecto a los marcos genéricos, el que más se repitió es el de atribución de responsabilidad en los textos recogidos en El País con la segunda Ley del divorcio.

\section{Conclusiones/Discusión}

$A B C$ no se posicionó sobre el divorcio, como se deduce tras comprobar que este periódico no publicó editoriales sobre la segunda Ley y solo uno sobre la primera, sin incluir la opinión del diario sobre este asunto, a pesar de que se trataba de una normativa de gran relevancia social y política en la joven democracia española.

Mientras tanto, la UCD estaba fracturada al existir variedad de opiniones en la formación política respecto a la aprobación del divorcio en España, aunque fue el partido que impulsó esta legislación. Este paralelismo entre $A B C$ y la UCD guarda una relación directa, ya que el diario compartía muchos de sus principios con el Gobierno de Adolfo Suárez y con su corriente política.

El País tampoco publicó un número elevado de artículos de opinión sobre el divorcio. Al igual que $A B C$, solo incluyó un editorial con la primera ley, aunque en este caso sí que se 
posicionó claramente a favor de esta medida, coincidiendo así, además, con los principios editoriales de este diario. Sin embargo, el diario de Prisa emplea más imágenes en ambas leyes que $A B C$. Esto indica que El País mostró un mensaje visual vinculado a un hecho noticioso relativo al divorcio donde, además, aparecieron marcos genéricos, especialmente los de conflicto y atribución de la responsabilidad.

Cabe resaltar la escasa y casi nula presencia de información sobre movimiento feminista de España sobre el divorcio, a pesar de que El País se define como defensor de este movimiento. Este diario contradijo, por lo tanto, su línea ideológica. Aunque $A B C$ no se posicionó sobre el divorcio en el único editorial que tiene sobre la primera regulación de esta materia en la etapa democrática española, es el periódico que más marcos genéricos reúne en los textos periodísticos que aparecen en torno a una ley de las estudiadas (55 con la primera regulación). Por lo tanto, $A B C$ ofreció de manera latente su postura acerca de la primera legislación sobre el divorcio que se aprobó en democracia.

La escasa repercusión periodística de la segunda Ley del divorcio vino dada por dos cuestiones que llevaron a esta normativa a un tercer plano mediático. Se trata de la aprobación del matrimonio homosexual, que tuvo lugar el mismo día, y de la muerte del Papa Juan Pablo II. Esta circunstancia generó un clima mediático focalizado en la religión católica, el concepto del matrimonio, la libertad, el papel del Estado y las políticas denominadas sociales. Las referencias periodísticas que aparecieron en la prensa analizada estuvieron muy vinculadas a los valores progresistas, que se han impuesto sobre los marcos conservadores, impulsando así un pluralismo filosófico frente al monismo filosófico en los asuntos que guardan relación con los valores sociales y que, según la revisión teórica hecha, era el que imperaba en los años previos a la llegada de la democracia.

La legalización del divorcio - que fue previa a otras iniciativas legislativas de gran impacto político y social como el aborto o el matrimonio homosexual- provocó la exposición en la prensa española de planteamientos aperturistas en lo ideológico que acabaron con los principios heredados del anterior régimen político. Por lo tanto, la prensa española - tanto la progresista como la conservadora - fue una buena herramienta para observar la aparición de la pluralidad social y aperturista que surge en España con la llegada de la democracia. El divorcio sentó las bases de un esquema político y mediático que se ha reproducido posteriormente, compuesto por el conflicto entre la Iglesia y el Estado, el poder de los medios de comunicación en asuntos de índole ética y jurídica y por las profundas discrepancias internas y la falta de determinación de los partidos de centro-derecha.

\section{Bibliografía}

$A B C$ (2010). «Principios, pensamientos y rigor». $A B C, 10$ de noviembre, 22. Recuperado de https://www. abc.es/medios/20131110/abci-principios-pensamiento-rigor-201311100629.html?ref=https:\%2F\%2Fwww.google.com\%2F

ANDRÉU, Jaime (2001). «Las técnicas de Análisis de Contenido: Una revisión actualizada». Fundación Centro Estudios Andaluces, 10(2), p. 1-34.

BELLOCH, S. (1998). «Para acabar con Felipe González se llegó a rozar la estabilidad del Estado».

Revista Tiempo, 14 de febrero, p. 825.

BERELSON, B. (1952). Content analysis in comunication tesearch. Glencoe: Free Press. 
BOCG (1980). «Congreso de los Diputados, I Legislatura, serie A, Proyecto de ley». Boletín Oficial de las Cortes Generales, 13 de marzo de 1980, núm. 123 I, 855-867.

BOE (1978). «Constitución Española» Boletín Oficial del Estado, 311, págs. 29313 a 29424, 29 de diciembre. BOE (2005). «Ley 15/2005, de 8 de julio, por la que se modifican el Código Civil y la Ley de Enjuiciamiento Civil en materia de separación y divorcio". Boletín Oficial del Estado, 163, 9 julio.

CANEL CRESPO, María José (1999). «EI País, ABC y El Mundo. Tres manchetas, tres enfoques de las noticias». Zer, 6.

CASERO-RIPOLLÉS, Andreu (2009). «El control político de la información periodística». Revista Latina de Comunicación Social, 64, 354-366. DOI: 10.4185/RLCS-64-2009-828-354-366

CEBRIÁN, Juan Luis (1976). «El País que queremos». El País, 4 de mayo.

CRUZ, Juan (1996). Una memoria de El País. 20 años de vida en una redacción. Barcelona: Plaza y Janés editores.

D'ADAMO, Orlando, GARCÍA BEAUDOUX, Virginia y FREIDENBERG, Flavia (2007). Medios de comunicación y opinión pública. Madrid: Mc Graw Hill.

DE VREESE, Claes H., PETER, Jochen y SEMETKO, Holli A. (2001). «Framing politics at the launch of the Euro: A cross-national comparative study of frames in the news». Politicalcommunication, 18(2), 107-122.

DOMÍNGUEZ, Andrés (2007). «La supresión de las causas de separación y divorcio en la ley 15/2005 y sus repercusiones en el Derecho Civil». Revista Jurídica de Castilla y León, 13, 57-58.

ECHART ORÚS, Nazareth, VILLAGRÁ GARCÍA, Nuria, BENAVIDES DELGADO, Juan y CANEL CRESPO, María José, (2006). «Los medios de comunicación, puentes para la representación política». En Martínez, Antonia (Coord.). Representación y calidad de la democracia. Madrid: Tecnos.

EDO, Concha (1994). La crisis de la prensa diaria. Barcelona: Ariel Comunicación.

EL PAíS (1976). «Ante la "Reforma"». El País, 4 de mayo. Recuperado de https://elpais.com/diario/1976/05/04/portada/200008801_850215.html

EL PAís (2009). «Kosovo por dentro». El País, 26 de marzo, p. 4. Recuperado de https://elpais.com/ diario/2009/03/26/opinion/1238022001_850215.html

ENTMAN, Robert M. (1991). «Symposium framing US coverage of international news: Contrasts in narratives of the KAL and Iran air incidents». Journal of communication, 41(4), 6-27. DOI: 10.1111/ j.1460-2466.1991.tb02328.x

ENTMAN, Robert M. (1993). «Framing: toward clarification of a fractured paradigm». Journal of communication, 43(4), 51-58. DOI: 10.1111/j.1460-2466.1993.tb01304.x

ETURA, Dunia (2018). «La transformación del modelo de mujer a través del programa Informe Semanal: Análisis de contenido cuantitativo de los reportajes emitidos entre 1973-1978». Pensamiento al margen, 9, 37-67.

FERNÁNDEZ DEL RIESGO, Manuel (2012). Homosexualidad y aborto: cuestiones de ética sexual. Madrid: Escolar y Mayo Editores S.L.

FERNÁNDEZ-RAMOS, María Yolanda y ANTÓN CRESPO, Margarita (2018). «Estereotipos de las personas mayores y de género en la prensa digital: estudio empírico desde la teoría del framing". Prisma social, 21, 317-337.

GAHETE MUÑOZ, Soraya (2017). «Las luchas feministas. Las principales campañas del movimiento feminista español (1976-1981)». Revista de Investigaciones Feministas, 8(2), 583-601. DOI: 10.5209/INFE.54792

GARCÍA BEAUDOUX, Virginia y D’ADAMO, Orlando (2016). «Comunicación Política: narración de historias, construcción de relatos políticos y persuasión». Comunicación y Hombre, 12, 23-39. Recupe- 
rado de https://comunicacionyhombre.com/article/comunicacion-politica-narracion-historias-construccion-relatos-politicos-persuasion/

GOMIS, Lorenzo (1987). El medio media, la funciónpolítica de la prensa. Madrid: Seminarios y ediciones DL. LUCA DE TENA, G. (1980). «Razones para una fidelidad». ABC, 2 de junio, p. 4.

MANFREDI, Juan Luis (2000). Manual de producción periodística. Sevilla: Editorial MAD.

MARTÍN DE SANTA OLALLA, Pablo (2001). «La ley del divorcio de junio de 1981 en perspectiva histórica». Revista Espacio, Tiempo y Forma, 14, 519-551.

MARTÍN DE SANTA OLALLA, Pablo (2019). «Iglesia católica y democracia. La aportación del catolicismo al cambio político en España». Miscelánea Comillas. Revista de Ciencias Humanas y Sociales, 77(150), 57-81.

MARTÍNEZ ALBERTOS, José Luis (1991). Curso general de redacción periodística. Madrid: Thomson.

MARTÍNEZ ALBERTOS, José Luis (2001). «El mensaje periodístico en la prensa digital». Estudios sobre el Mensaje Periodístico, 7, 19-32.

MCCOMBS, Maxwell (2006). Estableciendo la agenda. El impacto de los medios. Barcelona: Paidós Ibérica.

MITCHELL, Kierra (2019). Camino a la interseccionalidad: Una aproximación al desarrollo de Ideas feministas en la España contemporánea. Scripps Senior Theses.

MONTERO, Justa (2004). «Movimiento feminista: una trayectoria singular». Mientras Tanto. 91/92, 107-121.

MONTERO AROCA, Juan, FLORS MATíES, José y ARENAS GARCÍA, Rafael (2006). Separación y divorcio. Tras la Ley 15/2005. Valencia: Tirant lo Blanch.

OLIVERA ZALDÚA, María (2013). «Abcfoto. Análisis del proyecto fotográfico documental del diario $A B C$. Cuadernos de Documentación Multimedia, 24, 77-85. DOI: 10.5209/rev_CDMU.2013.v24.46284

OLMOS, Víctor (2002). Historia del ABC. Barcelona: Plaza y Janés.

PORTA, Luis y SILVA, Miriam (2003). «La investigación cualitativa. El análisis de contenido en la investigación educativa». Anuario Digital de Investigación Educativa, 14, 388-406.

PSOE (2004). Programa electoral del PSOE a las Elecciones Generales.

ROCA, Nuria y CERVI, Laura (2017). «La modernización de la campaña electoral para las elecciones generales de España en 2015. ¿Hacia la americanización?». Comunicación y Hombre, 13, 133-150. Recuperado de https://comunicacionyhombre.com/article/la-modernizacion-la-campana-electoral-las-elecciones-generales-espana-2015/

RODRÍGUEZ-LUQUE, Cristina (2008). «Tratamiento periodístico de las "células madre" desde la perspectiva del Framing. El País y ABC (1996-2006)». Doxa comunicación, 7, 165-171. DOI: 10.31921/ doxacom.n7a9

SÁNCHEZ ARANDA, José Javier y BERGANZA, Rosa (1999). «Framing en la prensa española: La información sobre la muerte y funeral de Diana de Gales». Comunicación y Sociedad, XII, 1, pp. 137-161.

SANMARTÍ ROSET, Josep M. (2001). «Los nuevos mediadores en el periodismo político». Binaria: Revista de comunicación, cultura y tecnología, 1, 1579-1300.

SEGADO BOJ, Francisco (2009). «El camino a las elecciones de 1977: El primer Gobierno de Adolfo Suárez en las viñetas de la prensa diaria». Revista Hispania, 69(232), 477-512.

SEMETKO, Holli A. y VALKENBURG, P. M. (2000). «Framing European politics: a content analysis of press and television news». Journal of Communication, 2(50). DOI: 10.1111/j.1460-2466.2000. tb02843.x

SEOANE, María Cruz y SUEIRO, Susana (2004). Una historia de El País y del Grupo Prisa. Barcelona: Editorial Plaza y Janés. 